\title{
THE CAPACITY DESIGN OF REINFORCED CONCRETE HYBRID STRUCTURES FOR MULTISTOREY BUILDINGS
}

\author{
T. Paulay ${ }^{1}$ and W. J. Goodsir ${ }^{2}$
}

\begin{abstract}
SYNOPSIS
To complement existing capacity design procedures used in New Zealand for reinforced concrete buildings in which earthquake resistance is provided by ductile frames or ductile structural walls, an analogous methodology is presented for the design of ductile hybrid structures. Modelling and types of structures in which the mode of wall contribution is different are briefly described. A step by step description of a capacity design procedure for a structural system in which fixed base ductile frames and walls, both of identical height, interact, is presented. The rationale for each step is outlined and, where necessary, evidence is offered for the selection of particular design parameters and their magnitudes. A number of issues which require further study are briefly outlined. These relate to irregularity in layout, torsional effects, diaphragm flexibility, shortcomings in the predictions for dynamic shear demands in walls, and to limitations of the proposed design procedure. It is believed that the methodology is logical, relatively simple and that it should ensure, when combined with appropriate detailing, excellent seismic structural response.
\end{abstract}

\section{INTRODUCTION}

When lateral load resistance is provided by the combined contributions of ductile multistorey frames and structural walls, the system is often referred to as a "hybrid structure". In North America, the term "dual system" is used. These structures combine the advantages of their constituent components. Because of the large stiffness of walls which are provided with adequate restraints at the foundations, excellent storey drift control may be obtained. Moreover, suitably designed walls can ensure that storey mechanisms (soft storeys) will not develop in any event. Interacting ductile frames on the other hand, while carrying the major part of the gravity load, can provide, when required, significant energy dissipation, particularly in the upper storeys.

Despite the attractiveness and indeed existence of many such structures in New Zealand, comparatively little research effort has been directed to them. The New Zealand Code of Practice for Design of Concrete Structures ${ }^{1}$ draws designers" attention to the need for "special studies" when designing "ductile hybrid structures". No specific guidance is, however, provided. Known studies refer primarily to elastic response, despite the obvious importance of the features of inelastic behaviour.

A study was initiated with the aim of ultimately formulating a design procedure for hybrid structures which would be analogous to those developed in New Zealand for ductile frames and ductile structural walls 1 . It was hoped that a scheme could be formulated which would provide a smooth transition between design approaches for space frames*l and those for buildings in which seismic resistance is provided by structural walls only*1,2. To this end numerous analytical studies of prototype building structures were conducted 3,4 to provide appropriate calibration of the principal design parameters. This paper reports on the findings and conclusions as they relate to design procedures rather than on details of features of structural behaviour.

The traditional procedure of designing for earthquake resistance, utilizing elastic analysis techniques and equivalent lateral static loads, is well established. The resulting distribution of lateral load resistance over the height of buildings with ductile frames, or structural walls, is generally accepted as meeting satisfactorily actual earthquake load demands. There was little evidence to indicate that this would be the case also with hybrid structures. One source of concern for possibly drastic differences between "elastic static" and "elasto-plastic dynamic" responses of hybrid structures stems from the recognition of fundamental differences in the behaviour of

* Details of the "capacity design" of reinforced concrete structures are given in NZS 3101:1982 and the background to this design philosophy is outlined in some detail in the commentary of the code of practice.

1 Professor of Civil Engineering, University of Canterbury, New Zealand.

2 Engineer, Ove Arup Partnership, London, England. 
beam-column frames and structural walls. These differences stem from dissimilar deformation patterns when subjected to the same lateral load, as shown in Fig. 1 . Frames and walls, while sharing in the resistance of shear forces in the lower storeys, oppose each other in the storeys near the top of the building. It was of major interest to examine the load sharing between these two types of interacting elements during inelastic dynamic response to a major seismic event.

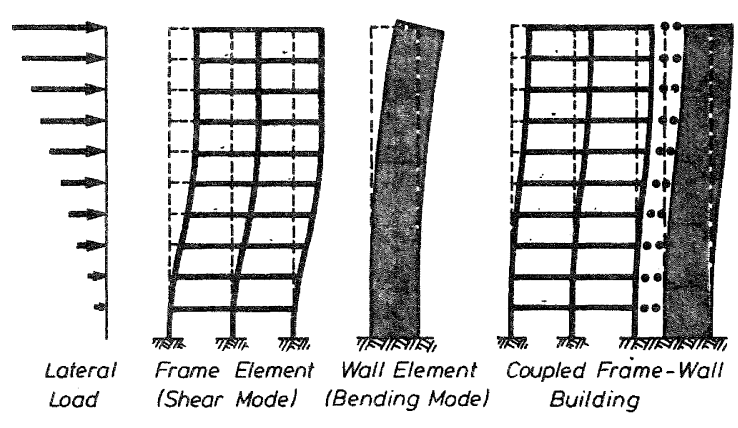

Fig. 1 Deformation Patterns of Laterally Loaded Frame, Walls and Coupled Wall-Frame Elements.

A step by step design methodology is proposed, to meet the intent of the "capacity design" philosophy. The presentation concentrates solely on issues relevant to the largest expected seismic event envisaged by the code ${ }^{5}$. The emphasis is therefore on issues of ductility and the prevention of collapse. Existing procedures, to satisfy design criteria for stiffness and minimum strength, both relevant primarily to damage control, and considered to be equally applicable to hybrid structures, are not referred to in this paper.

The dominant feature of the capacity design strategy is the a priori establishment of a rational hierarchy in strength between the components of the entire structural system. Accordingly, the approach to the design of each primary lateral load resisting component which is to be protected against yielding or brittle failure, such as due to shear. can be described by the simple general expression for the ideal strength $S_{i}$, thus

$$
s_{i} \geqq \omega \phi_{O} s_{\text {code }}
$$

where $S$ is the required dependable strength ${ }^{c}$ die the member selected for energy dissipation, as determined by elastic analysis techniques for a code ${ }^{5}$ specified lateral static load on the structure; $\phi$ is the ratio of the maximum strength, $S^{\circ}$, which can be developed in the selected inelastic component (as built) by large displacements during a severe seismic event, to the strength required, S.
for the same member by the code specilied lateral loading; and $w$ is a dynamic magnification factor which quantifies deviations in strength demands on the member to be protected, from demands indicated by elastic analysis. Extreme demands are expected to occur during the inelastic dynamic response of the structure.
For the sake of completeness, certain aspects of the "capacity design" of ductile frames are restated.

\section{TYPES OF HYBRID STRUCTURES AND}

In the following, some distinct and common types of hybrid structures, in which walls and frames interact in a particular manner, are described. No attempt is made, however, to categorize all possible combinations in which these two systems may be utilized. Conventional modelling techniques, to be used for the purposes of analysis, are briefly reviewed and suggestions made for choices of suitable energy dissipating systems in hybrid structures.

\subsection{Interacting Ductile Frames and Ductile Cantilever Walls}

In the majority of reinforced concrete multistorey buildings, lateral load resistance is assigned to both ductile space frames and cantilever structural walls. Figure 2 (a) shows in pian the somewhat idealized symmetrical disposition of frames and walls in a 12 storey example building. The properties of these two distinct structural elements may be conveniently lumped into a single frame and a single cantilever wall, as shown in Fig. 2 (b). Instead of individual walls, shown in Fig. 2(a), tubular cores, or coupled structural walls, are also used frequently.
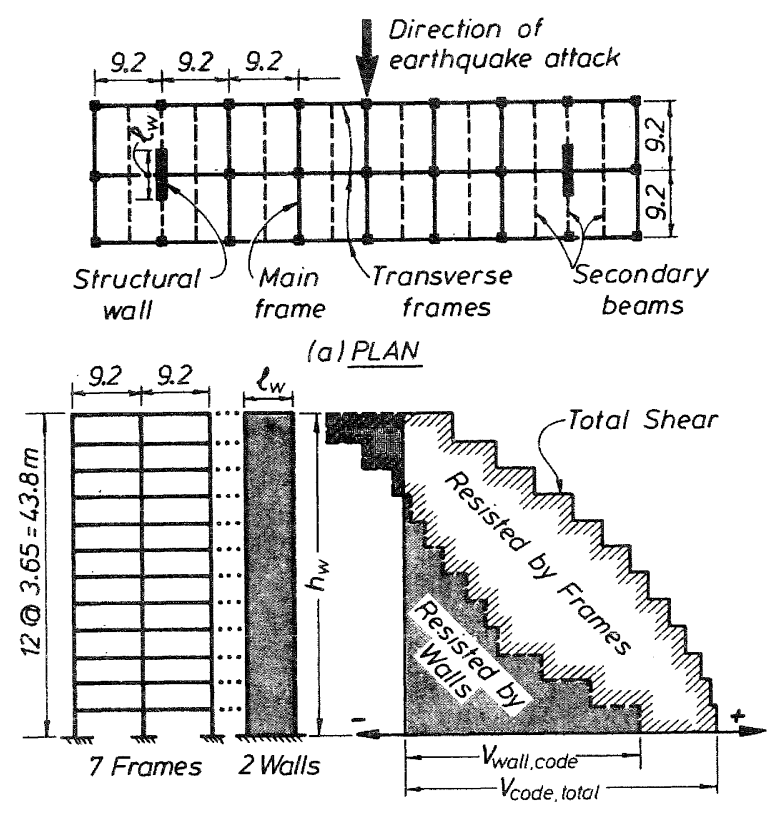

(b) STRUCTURAL MOOELLING (c) STOREY SHEAR FORCES

Fig. 2 Modelling of and Lateral Load Sharing in a Typical Wall-Frame System.

It is customary to assume that floor slabs at all levels have infinite inplane rigidity. Such diaphragms will then ensure that storey displacements for frames and walls are the same or that in the case of storey torsion, a simple linear relationship exists between the storey displacements of vertical

elements. When diaphragms are relatively slender and when large concentrated lateral storey forces need to be introduced to 
relatively stiff walls, particularly when these are spaced far apart, the flexibility of floor diaphragms may need to be taken into account. This issue is briefly reviewed in section 4.3 .

The extensionally infinitely rigid horizontal connection between lumped frames and walls at each floor, shown in Fig. 2(b). enables the analysis of such laterally loaded elastic structures to be carried out speedily. Typical results are shown in Fig. 2(c). Here the sharing between walls and frames of the total storey shear forces is illustrated. The relative participations which reflect the behaviour of the two different systems, as shown in Fig. 1 . indicate a rapid decline with height of the contribution of the walls to shear resistance. Figure 2 (c) also shows how the two systems oppose each other in the top storeys. The distribution of magnitudes of shear forces with height for each system will depend primarily on the relative stiffnesses of the walls and frames. This example structure, shown in Fig. 2 , will be subsequently used to illustrate typical distributions of forces and moments for both walls and frames, as a consequence of inelastic dynamic response to seismic excitations.

As the flexural response of walls is intended to control deflections in hybrid structures, the danger of developing "soft storeys" should not arise. The designer may therefore freely choose those members or localities in frames where energy dissipation should take place when required. A preferable and practical mechanism for the frame of Fig. 2 is shown in Fig. 4(a). In this frame, plastic hinges, when required during a large expected seismic event, are made to develop in all the beams and at the base of all vertical elements. At roof level, plastic hinges may form in either the beams or the columns. The main advantage of this system is in the detailing of the potential plastic hinges. Generally it is easier to detail beam rather than column ends for plastic rotation. Moreover, the avoidance of plastic hinges in columns allows lapped splices to be constructed at the bottom end rather than at midheight of columns in each upper storey.

The design procedure described in considerable detail in section 3 , is relevant to this type of structural system and its preferred energy dissipating mechanisms.

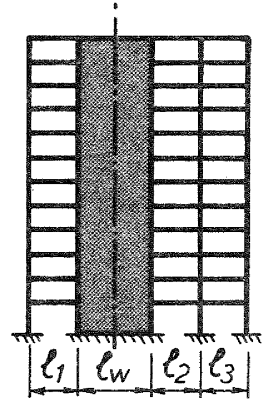

(a)

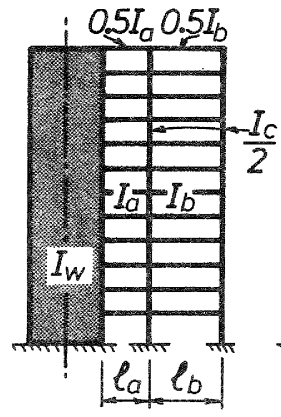

(b)

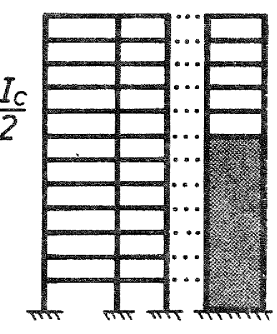

(c)

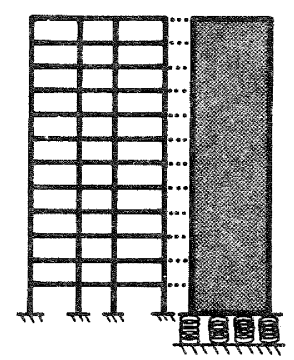

(d)

Fig. 3 Modelling of Different Types of Hybrid Systems. 
Simplified analysis techniques, useful at least for preliminary design, have been developed for such a mixture of interacting frames and walls ${ }^{6}$. The structural idealization used in shown in Fig. 3(b). The stiffness of all walls, as quantified by the second moment of area, are lumped into a stiffness, $I$, of a single wall. Where appropriate Wllowance for shear distortions in the walls should also be made ${ }^{2}$. The beams framing directly into wall edges, i.e. those with span lengths $\ell_{1}$ and $\ell_{2}$ in Fig. 3 (a), are lumped at each 1 loor into a single beam having a mean second moment of area. I, and span $\ell$, as shown in Fig. $3(b)$. AII other beams, such as span $\ell_{3}$ in Fig. 3(a) and the beams of the frames ${ }^{3}$ in Fig. 2(a), are also lumped and replaced at each floor with beams having the mean properties of $I_{b}$ and $\ell_{b}$ shown in Fig. 3(b). The aim is to obtain representative mean $\mathrm{I} / \mathrm{l}$ ratios for the beams. Finally all the columns of the buildings are lumped into two identical columns, each having one half of the moment inertia, $0.5 \mathrm{I}$, of the sum of the moment of inertia of alf columns of the real structure. Standard solutions for a range of relative stiffnesses have been presented for this type (Fig. 3(b)) of structure 6 .

Another useful technique replaces all frames with a single equivalent "shear" cantilever and connects this continuously over the height of the building to a single equivalent "bending" cantilever wall7. The method is similar to that used in the "laminar analysis" of coupled structural walls. It is limited to regular structures with vertically constant geometric properties.

Before the design of individual members can be finalised, it is necessary to identify clearly the locations in beams and columns at which plastic hinges are intended in order to enable the capacity design procedure to be applied.

\subsection{Frames Interacting with Walls of Partial Height}

Although in most buildings structural walls extend over the full height, there are cases when for architectural or other reasons, walls are terminated below the level of the top floor. A model of such a structure is shown in Fig. $3(\mathrm{c})$.

Because of the abrupt discontinuity in total stiffnesses at the level where walls terminate, the seismic response of these structures is viewed with some concern. Gross discontinuities are expected to result in possibly critical features of dynamic response which are difficult to predict. It is suspected that the regions of discontinuity may suffer premature damage and that local ductility demands during the largest expected seismic events might exceed the ability of affected components to deform in the plastic range without significant loss of resistance.

on the other hand, elastic analyses for lateral static loads show that structural walls in the upper storeys may serve no useful structural purpose. Figure 2 suggests that the termination of walls below the top floor may beneficially affect overall behaviour.
The response of such structures has also been studied recentiyli. A limited number of case studies, using the 1940 El Centro earthquake record, suggested no features that could not be readily accommodated in currently used design procedures. The findings of this study, together with the appropriate application of the capacity design approach, will be reported separately.

2.4 Hybrid Structures with Walls on Deformable Foundations

It is customary to assume that cantilever walls are fully restrained against rotations at the base. It is recognised, however that full base fixity for such large structural elements is very difficult, if not impossible, to achieve. Foundation compliance may result from soil deformations below footings and/or from deformations occurring within the foundation structure, such as piles. Base rotation is a vital component of wall deformations. Therefore it may significantly affect the stiffness of cantilever walls and hence possibly their share in the lateral load resistance within elastic hybrid structures. The reluctance to address the problem may be attributed to our limitations in being able to estimate reliably stiffness properties of soils. Moreover, soil stiffness is generally very different for static and dynamic loading. For the latter, frequency and amplitude are also parameters which affect soil response.

To gauge the sensitivity of hybrid structures of the type shown in Fig. 2 (b) with respect to fourdation compliance of the wall elements only, parametric studies were conductedll. The major variables in the structures chosen for analyses were:

(1) Variation of wall restraint between the extreme limits of full rotational fixity and a hinge at the base.

(2) Variation in the number of storeys in a building. Predominantly 6 and 12 storey structures were studied.

(3) The relative contribution of walls to total lateral load resistance within the structure were varied. This was achieved with appropriate variation of wall lengths, $l{ }^{\prime}$ shown in Fig. $2(\mathrm{a})$.

(4) Elastic response to code specified lateral static load was compared with the elasto-plastic dynamic response of the structure to the $1940 \mathrm{El}$ Centro earthquake record.

Details of this study are to be reported. Those aspects of the conclusions which are particularly relevant to the issues examined in this paper are as follows:

(a) Above the first floor, the static response of the structure with walls with moderate stiffness is not significantly affected by the degree of base restraint. As a corollary, the stiffer a wall the more profound is the influence of foundation compliance.

(b) In pinned base walls, as expected, very large and reversed base shear forces are predicted by elastic analyses for static lateral load. This points to the need for studying the transfer of these large forces to the diaphragm at 
first floor level. The wall shear reversals in the first storey necessitated dramatic increases in column shear forces in that storey. In the first storey the sum of the column shear forces exceed therefore the total static base shear for the entire structure.

(c) The single most important parameter affecting the seismic dynamic response of such hybrid structures was found to be the period shift brought about by the reduction of wall stiffnesses when complete loss of rotational restraint at the base was assumed.

(d) Extreme levels of shear forces, predicted by elastic analyses for columns and walls, did not eventuate during the time history analysis for the El Centro event.

(e) In the upper storeys important design quantities for the example hybrid structures, such as drifts, column and wall moments, and rotational ductility demands in plastic hinges of beams, were only insigniciantly affected when walls were modelled with pinned bases.

(f) Full wall base fixity is normally assumed in design, although it is known to be generally unavailable. These parametric studies indicated, however, that errors due to quite significant relaxation in base restraint, are not likely to seriously affect elasto-plastic dynamic response.

Brief comparisons of a few features of the analytically predicted response of prototype hybrid structures with fixed or pinned based walls, are made in section 3 .

\section{DETAILS OF A CAPACITY DESIGN}

In the following sections a capacity design approach for hybrid structures is described in a step-by-step manner. The presentation follows the pattern of and is similar to the design procedure suggested for reinforced concrete ductile frames in the Commentary of NZS 31011. Where necessary, the presentation of a design step is followed by comments, sometimes extensive. These are relevant to the purpose of and intend to explain the justification for that particular step. Frequent reference is made to Fig. 2, which shows a prototype framewall structure.

The procedure outlined in the following 19 steps is relevant to the types of structures shown in Figs. $4(a)$ and (b). In these columns in upper storeys are intended to be protected against significant plastic deformations. Thereby various concessions with respect to their detailing for ductility may be utilised.

Step 1 - Derive the bending moments and shear forces for all members of the frame-shear wall system subjected to the code specified equivalent lateral static earthquake load only. These actions are subscripted "code".
In the analysis for the elastically responding structure, due allowance should be made for the effects of cracking on the stiffness of both frame members and walls. Both frames and walls may generally be assumed to be fully restrained at their base. Load effects are referred to as $E$.

Step 2 - Superimpose the beam bending moments obtained in step 1 upon corresponding beam moments which are derived for appropriately factored gravity loading on the structure.

This superposition corresponds with the combinations of factored loads $U=D+1.3 L_{R}$ $\pm E$, where $D$ is the dead load and $L_{R}$ is the live load reduced as the tributary area increases 5 .

Step 3 - If advantageous, redistribute design moments obtained in Step 2 horizontally at a floor between any or all beams in each bent, and vertically between beams of the same span at different floors.

In the process of moment redistribution, the peak values of beam moments, resulting from the load combinations $U=D+1.3 L$ $\pm \mathrm{E}$, may be reduced by up to $30 \% \mathrm{I}^{+}$. However, the curtailment of the beam flexural reinforcement along a beam must be such that at least $70 \%$ of the moment obtained from elastic analyses in Step 2 can be resisted ${ }^{1}$. Final moments obtained after redistribution should be checked to ensure that no loss in the total lateral load resistance of the structure results ${ }^{8}$. Also combinations for gravity load alone, $\mathrm{U}=1.4 \mathrm{D}+1.7 \mathrm{~L}$, must be examined before the proportioning of beams commences.

The principles of redistribution of moments at a level among different spans of beams within frames are well established, 8 . One of the advantages which may result is the reduction of the peak beam negative moment at an exterior column which is associated with the load combination $U=D$ $+1.3 \mathrm{I} R+\mathrm{E}$. The reduction is achieved at the expense of increasing the (usually non-critical) positive moment at the same section associated with the combination $\mathrm{U}=\mathrm{D}+1.3 \mathrm{~L}_{\mathrm{R}}+\overrightarrow{\mathrm{E}}$. In the latter case the - Factored gravity moments only

- Gravity and earthquake moments from elostic analysis

* After horizontal redistribution 1 After vertical redistribution

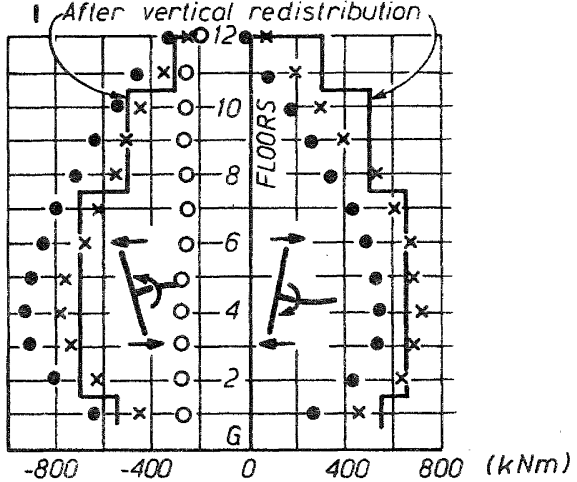

Fig. 5 The Redistribution of Design Moments Among Beams of a Hybrid Structure. 
gravity and earthquake moments, superimposed in Step 2, oppose each other. An example in Fig. 5 shows magnitudes of beam design moments at each floor at an exterior column at various stages of the analysis. The gravity moments (always negative), shown by circles, are changed by the addition of earthquake moments $\vec{E}$ or $\vec{E}$, to values shown by solid circles.

Because near their base, walls make very significant contributions to the resistance of both horizontal shear (Fig. 2) and overturning moment, the flexural demands on the beams of hybrid structures are relatively small in the lower storeys. The distribution of beam and wall moment demands with the height of the elastic structure depends on the relative stiffness of walls and frames ${ }^{3}$. In the example frames, the beam moments at the exterior column could be redistributed so as to result in magnitudes shown by crosses in Fig. 5. It is seen that the negative and positive moment demands are now comparable in magnitudes.

To optimize the practicality of beam design, whereby beams of identical strength are preferred over the largest possible number of adjacent floors, some vertical

redistribution of beam design moments should also be considered. In the example of Fig. 5, the design moments shown by crosses may be redistributed up and down the frames so as to result in magnitudes shown by the continuous stepped lines. It is seen that beams of the same flexural strength could be used over 6 floors. The stepped line has been chosen in such a way that the area enclosed by it is approximately the same as that within the curve formed by the crosses. This choice means that the contribution of the frames to the resistance of overturning moments is only insignificantly altered by vertical moment redistribution.

It may be noted that horizontal redistribution of beam moments at a particular level will change the moment input to individual columns. Hence the shear demand across individual columns will also change with respect to that indicated by the elastic analysis used in step 1. However, the total shear demand on columns of a bent must not change. This is referred to as

redistribution of design shear forces between columns.

When vertical redistribution of beam moments is carried out, the total moment input to some or all columns at a floor will also change. Hence the total shear demand on columns of a particular storey may decrease (the 5 th storey in Fig. 5), while in other storey (the 2nd storey in Fig. 5) it will increase. To ensure that there is no decrease in the total storey shear resistance intended by the code specified lateral loading, there must be a horizontal redistribution of shear forces between the vertical elements of the structure, i.e. columns and walls. It will be shown subsequently that the upper regions of walls will be provided with sufficient shear and flexural strength to accommodate additional shear forces shed by upper storey columns. The principles involved in vertical load redistribution discussed here are similar to those used in the design of coupling beams of coupled structural walls ${ }^{2}$

To safeguard against premature yielding in beams during small earthquakes, the reduction of beam moments resulting from combined horizontal and vertical moment redistribution should not exceed $30 \%$.

Step 4 - Design all critical beam sections so as to provide the required dependable flexural strengths, and detail the reinforcement for all beams in all Erames.

These routine steps require the determination of the size and number of reinforcing bars to be used to resist moments along all beams in accordance with the demands of moment envelopes obtained after moment redistribution. It is important at this stage to locate the two potential plastic hinges in each span (Fig. 4(a)) for each direction of earthquake attack. In locating plastic hinges which require the bottom (positive) flexural reinforcement to yield in tensign, both load combipations $U=D+$ 1. $3 \mathrm{~L}+E$ and $U=0.9 D+\vec{E}, 5$ should be considered, as each combination may indicate a different hinge position. Detailing of the beams should then be carried out in conformity with the relevant codel provisions.

Step 5 - In each beam determine the flexural overstrength of each of the two potential plastic hinges corresponding with each of the two directions of earthquake attack.

The procedure, incorporating allowances for strain hardening of the steel and the possible participation in flexural resistance of all reinforcement present in the structure as built, is the same as that used in the design of beams of ductile framesl. The primary aim is to estimate the maximum moment input from beams to adjacent columns associated with the largest seismic event.

Step 6 - Determine the lateral displacement induced shear force, $V$ associated with the development of flexural overstrength at the two plastic hinges in each beam span for each direction of earthquake attack.

These shear forces are readily obtained from the flexural overstrengths of potential plastic hinges, determined in step 5, which were located in step 4 . When combined with gravity induced shear forces, the design shear envelope for each beam span is obtained, and the required shear reinforcement can then be determined ${ }^{1}$. The displacement induced maximum beam shear forces, $V$, are used subsequently to determine the maximum lateral displacement induced axial column load input at each floor.

Step 7 - Determine the beam flexural overstrength factor, $\phi^{\prime}$, at the centre line of each column at each floor for both directions of earthquake attack. Fixed values of $\phi$ are:

(a) At ground level $\phi_{0}=1.4$

(b) At roof level $\phi_{0}^{\circ}=1.1$. 
This factor is subsequently used to estimate the maximum moment which could be introduced to columns by fully plastified beams. The beam overstrength factor, $\phi$ at a column, is the ratio of the sum of the flexural overstrengths developed by adjacent beams, as detailed, to the sum of the flexural strengths required in the given direction by the code specified lateral earthquake loading alone, both sets of values being taken at the centre line of the relevant column ${ }^{1}$.

The beam moments at column centre lines can be readily obtained graphically from the design bending moment envelopes, after the flexural overstrength moments at the exact locations of the two plastic hinges along the beam have been plotted.

Step 8 - Evaluate the column design shear forces in each storey from

$$
\mathrm{v}_{\mathrm{COI}}=\omega_{\mathrm{C}} \phi_{\mathrm{O}} \mathrm{v}_{\text {code }}
$$

where column dynamic shear magnification factor, $\omega$, is $2.5,1.3$ and 2.0 for the bottom, intermediate and top storeys respectively. The design shear force in the bottom storey columns should not be less than

$$
v_{\mathrm{COI}}=\frac{\left(\mathrm{M}_{\mathrm{COI}}^{\mathrm{O}}+1.3 \phi_{\mathrm{O}}^{\mathrm{M}} \mathrm{code}\right)}{\left(l_{\mathrm{n}}+0.5 \mathrm{~h}_{\mathrm{b}}\right)}
$$

where $M_{\mathrm{COI}}^{O}=$ the flexural overstrength of the column base section consistent with the axial load and shear which are associated with the direction direction of earthquake attack.

$M_{\text {code, top }}=\frac{\text { the value of }}{\text { column at the code }} \frac{\text { for the }}{\text { oline }}$ of the first floor beams.

$l_{n} \quad=$ the clear height of the

$\mathrm{h}_{\mathrm{b}}=\frac{\frac{\text { column }}{\text { the depth of the first }}}{\text { floor beam }}$

The procedure for the evaluation of column design shear forces is very similar to that used in the capacity design of ductile frames ${ }^{l}$. It reflects a higher degree of conservation because of the intent to avoid a column shear failure in any event. Case studies show that in spite of the apparent severity of Eqs. (2) and (3), shear requirements very seldom govern the amount of transverse reinforcement to be used in columns.

Dynamic analyses of example hybrid structuresll indicated that shear forces induced in the bottom and top storey columns may exceed by a large margin the magnitudes prediçted by elastic (Step 1) analyses, $\mathrm{V}, 4$. It may be noted, however, that in code the computed static column shear forces, $\mathrm{V}$ are often very small in these two specífic storeys.

Step 9 - Estimate in each storey the maximum likely lateral displacement induced axial load on each column from

$$
\mathrm{P}_{\text {eq }}=\mathrm{R}_{\mathrm{v}} \Sigma \mathrm{V}_{\text {oe }}
$$

where $R_{V}=(1-n / 67) \geqq 0.7$

is a reduction factor which takes the number of floors, $n$, above the storey under consideration, into account.

The magnitudes of the maximum lateral displacement induced beam shear forces, $V$, at each floor, were obtained in step 6 . The probability of all beams above a particular level developing simultaneously plastic hinges at flexural overstrength diminishes with the number of floors above that level. The reduction factor, $R$, makes an approximate allowance for this.

Step 10 - Determine the total design axial load on each column for each of the two directions of earthquake attack from

$$
\begin{aligned}
\mathrm{F}_{e_{,}, \max } & =\mathrm{P}_{\mathrm{D}}+\mathrm{P}_{\mathrm{LR}}+\mathrm{P}_{\text {eq }} \\
\text { and } \mathrm{P}_{\mathrm{e}, \min } & =0.9 \mathrm{P}_{\mathrm{D}}-\mathrm{P}_{\text {eq }}
\end{aligned}
$$

where $P_{P}$ and $P_{\text {r }}$ are axial forces due to dead and reducêd live loads.respectively.

Step 11 - Obtain the design moments for columns above and below each floor from

$$
M_{\operatorname{col}}=R_{m}\left(\omega \phi_{0} M_{c o d e}-0.3 h_{b} V_{c o l}\right)
$$

\section{where $\omega=$ the dynamic moment magnification factor, the value of which is given in Fig. 6. \\ $\phi_{0}=$ the beam overstrength factor appli- cable to the floor and the direction of lateral loading under consider ation \\ $h_{\mathrm{b}}=$ Ehe depth of the beam which frames into the column}

and $R_{m}=1+0.55(\omega-1)\left(10 \frac{P_{e}}{F_{c}^{\prime} \bar{A}_{g}}-1\right) \leqq 1$

is a design moment reduction factor appliable when

$$
-0.15 \leq \frac{P_{e}}{f_{c} A_{g}} \leq 0.10
$$

Where $P_{e}$ is to be taken negative when causing axial tension.

These requirements are very similar to those recommended for columns of ductile frames 1 .

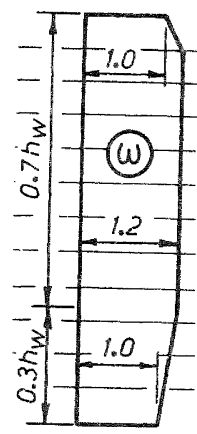

Fig. 6 Dynamic Moment Magnification Factor for Columns in Hybrid structures. 
The steps in the derivation of the column design moment, $M$, are given in Fig. 7 as follows. The varlation of column moments due to code loading (Step 1), M above and below a floor is shown with ${ }^{c}$ ghaded lines. These moments are magnified throughout the height of the column to $\phi M M$, when beams adjacent to the column develop flexural overstrengths at their plastic hinges. It is assumed that the maximum moment input from the two beams, $\Sigma M$, as shown in Fig. 7, cannot be exceededm during an earthquake. However, the distribution of this total moment imput between the columns above and below the floor, during the dynamic response, is uncertain. Allowance for disproportionate distribution is made by the dynamic magnification factor $\omega \leqq 1.2$. For example the estimated maximum moment for the upper column in Fig. 7, measured at the beam centre Iine, is thus $\omega \phi_{0} M_{c o d e}$. At the top of the beam, at the critical section of this column, the moment is less. The reduction depends on the magnitude of the column shear force generated simultaneously. For this purpose a conservative assumption is made, whereby $\mathrm{V}_{\text {min }}=0.6 \mathrm{~V}_{\mathrm{max}}=0.6 \mathrm{~V}_{\mathrm{col}}(\mathrm{step} 8)$. Hence the moment reduction at the top of the beam becomes $0.5 \mathrm{~h}_{\mathrm{b}} \mathrm{V}_{\min }=0.3 \mathrm{~h}_{\mathrm{b}} \mathrm{V}_{\mathrm{Col}}$ as shown in Fig. 7 .

When the axial load on the column produces small compression, i.e. $\mathrm{P}_{e} \leq 0.1 \mathrm{fl}_{\mathrm{C}}^{\prime} \mathrm{A}_{\mathrm{g}}$ or results in net axial tension, some ylelding of the column is not unacceptable. Sucin columns should exhibit sufficient ductility even without special confining reinforcement in the end regions. Hence for this situation the design moments are reduced by the factor $R_{m}$ given in Eq. (9). This expression will give the same values that have been recommended ${ }^{l}$ for columns of ductile frames, provided that the value of $\omega$ is not taken larger than 1.2. The minimum value of $R_{m}$ is 0.72 . This will enable the amount of required tension reinforcement in exterior column, where this situation arises, to be reduced.

Because the value of the dynamic moment magnification factor for columns in hibrid structures is relatively small, i.e. $\omega \leqq 1.2$, the above reduction of column desian moments will seldom exceed $20 \%$. To simplify computations, the designer may prefer to use $R_{m}=1.0$.

When the reduction factor, $R_{m}$, is used in determining the amount of column reinforcement, the design shear $\mathrm{V}_{\mathrm{Col}}$, obtained in Step 8 , may also be reduced proportionally.

Having obtained the critical design quantities for each column, $i . e$. M 11 and $V_{c o}$ from step 8 , the required flexural and shear reinforcement at each critical section can be found. Because the design quantities have been derived from beam overstrengths imput, the appropriate strength reduction factor for these columns is $\phi=1.01$. End regions of columns need further be checked to ensure that the transverse reinforcement provided satisfies the code 1 requirements for confinement, stability of vertical reinforcing bars and lapped splices.

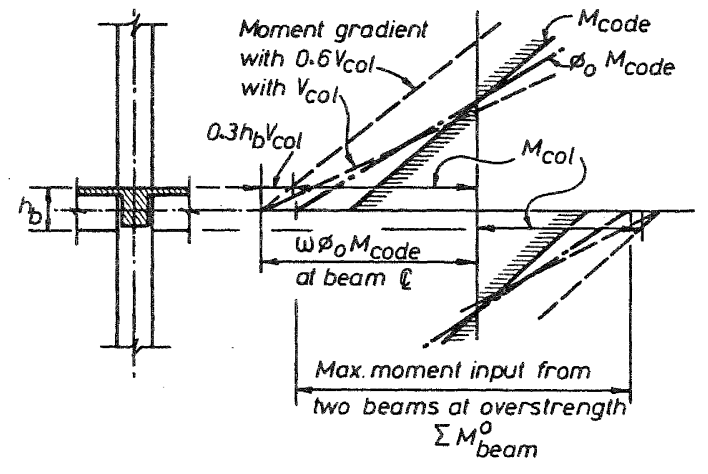

Fig. 7 The Derivation of Design Moments for Columns.

The design of columns at the base, where the development of a plastic hinge in each column must be expected, is the same as for columns of ductile frames ${ }^{1}$.

Step 12 - Determine the appropriate gravity and earthquake induced axial forces

\section{on walls}

In the example structure (Fig. 2), it was, implicitly assumed that lateral load on the building dues not introduce axial forces to the cantilever walls. For this situation the design axial forces on the walls are $\mathrm{P}_{\mathrm{e}}=\mathrm{P}_{\mathrm{P}}+1.3 \mathrm{P}_{\mathrm{R}}$ or $\mathrm{P}_{\mathrm{e}}=0.9 \mathrm{P}$. Generally the latter, when considered together with lateral load induced moments, governs the amount of vertical wall reinforcement to be used.

If wails are connected to columns via rigidly connected beams, as shown for example in Fig. 3(a), the lateral load induced axial forces on the walls are obtained from the initial elastic analysis of the structure (step 1). Similarly this applies when, instead of cantilever walls, coupled structural walls ${ }^{2}$ share with frames in lateral load resistance.

Stef 13 - Determine the maximum bending moment at the base of each wall and design the necessary flexural reinforcement, taking into account the most adverse combination with axial forces on the wall.

This simply implies that the requirements of strength design be satisfied. The appropriate combination of actions is $\mathrm{M}_{\mathrm{u}}=$ $\mathrm{M}_{\mathrm{Code}}$ and $\mathrm{P}_{\mathrm{l}}=\mathrm{P}_{\mathrm{e}}$. Because the wall should meet the additional seismic requirements specified by the code ${ }^{1}$, the appropriate strength reduction factor to be used is $\phi=0.9^{1}$, irrespective of the level of axial compression. The exact arrangement of bars within the wall section at the base, as built, is to be determined to allow the flexural overstrength of the section to be estimated. 
ldeal moment strength lo be

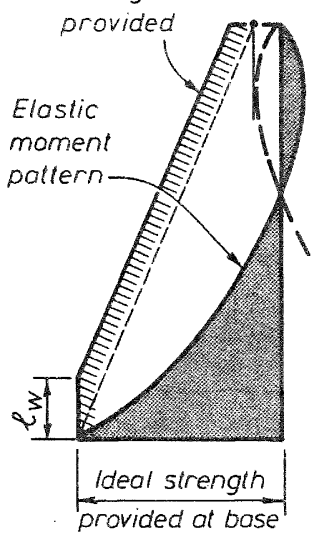

Fig. 8 Design Moment Envelope for Walls of Hybrid Structures.

Step 14 - When curtailing the vertical reinforcement in the upper storeys of walls, provide flexural resistance not less than given by the moment envelope in Fig. 8 .

The envelope shown is similar to but not the same as that recommended for cantilever walls ${ }^{l}$. It specifies slightly larger flexural resistance in the top storeys. Its construction from the injtial moment diagram, obtained from the elastic analysis in step 1 , may be readily followed in Fig. 8 . It is important to note that the envelope is related to the ideal flexural strength of a wall at its base, as built, rather than the moment required at that section by the analysis for lateral load. The envelope refers to effective ideal flexural strength. Hence vertical bars in the wall must extend by at least full development length beyond levels indicated by the envelope.

The aim of this apparently conservative approach is to ensure that significant yielding will not occur beyond the assumed height, $\ell_{\text {w }}$, of the plastic hinge at the base. Thereby the shear strength of the wall in the upper storeys is also increased ${ }^{l}$, and hence reduced amounts of horizontal shear reinforcement may be used.

Figure 9 compares wall moment demands, encountered during the analysis for the 1940 El Centro and the 1971 Pacoima Dam earthquake records, with the moment envelopes given in $\mathrm{Fig} .8$. Three 12 storey buildings, in plan as shown in Fig. 2, with walls of $3.0,3.6$ and 7.0 metres length, were studied. All buildings were designed in accordance with this capacity design procedure. While the envelopes appear to provide considerable reserve flexural strength in the upper storeys during the El Centro record, at various instants of the extreme (and unrealistic) Pacoima Dam event the analysis predicted the attainment of the ideal flexural strength in most storeys. Analyses showed, however, that curvature ductility demands, even during this extreme event, were very small in the upper storeys. As part of the study of the effects of foundation compliance, discussed in Section 2.4, these structures, with pinned base walls, but otherwise identical with the prototype structures, were also analysed for the El Centro record. It is seen in Fig. 9, that wall moment demands for the El Centro event in the upper storeys are very similar to those experienced with fixed base walls.

Step 15 - Determine the magnitude of the flexural overstrength factor $\phi$ w for each wall. This is the ratio of the flexural overstrength of the wall, $\mathrm{M}^{\mathrm{O}}$ as detailed, to the moment required to resist the code specified lateral loading, Mcode: both moments taken at the base section of a waI1

The meaning and purpose of this factor, $\phi_{O, W}=\left(M^{O} / \mathrm{M}_{\text {code }}\right.$,base $)$, is the same as that eváluated for beams in step 7. Strictly, for walls there are two limiting values of overstrength, $\mathrm{M}^{\circ}$, which could be considered. These are the moments developed in the presence of two different axial load intensities, i.e. $P_{e}, \max$ and $P_{e}$ min. However, it is considered to be sufficient for the intended purpose to evaluate flexural overstrength developed with axial compression on cantilever walls due to dead load alone ${ }^{2}$

Step 16 - Compute the wall shear ratio, $\psi$. This is the ratio of the sum of the shear forces at the base of all walls, $\sum V$. design, load, to the total design base shear For the entire structure, V code, total.

The relative contribution of all walls to the required total lateral load resistance is expressed as a matter of convenience by
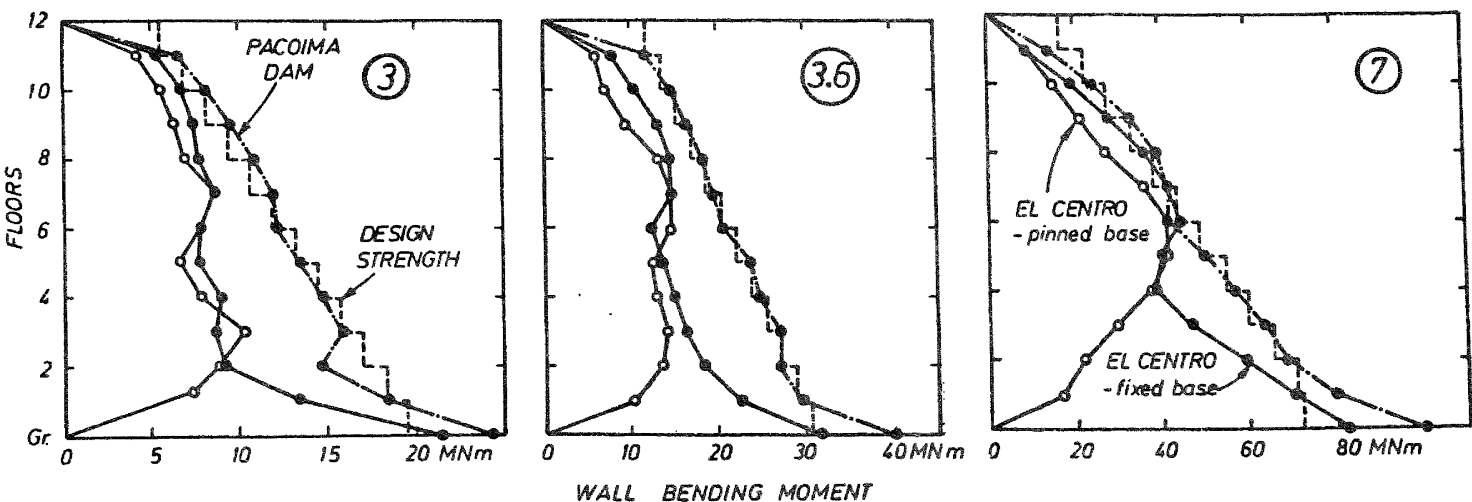

Fig. 9 Wall Moment Demands Encountered During Earthquake Records. 
the shear ratio

$$
\psi=\sum_{i=1}^{n} v_{i} \text {,wall, code } / v^{\prime} \text { code, total' base }
$$

It applies strictly to the base of the structure. As Fig. 2(c) shows, such a shear ratio would rapidly reduce with height, and near the top it could become negative. This indicates that the parameter $\psi$ is a convenient but not unique measure to quantify the share of walls in the total lateral load resistance.

Step 17 - Evaluate for each wall the design shear force at the base from

$$
\mathrm{v}_{\text {wall,base }}=\omega_{\mathrm{v}}^{*} \phi_{0}, \mathrm{w} \mathrm{v}_{\text {wall, code }}
$$

and

$$
\omega_{\mathrm{v}}^{k}=1+\left(\omega_{\mathrm{v}}-1\right) \psi
$$

where ${ }^{\prime} \mathrm{V}$ is the dyanmic shear magnification factor relevant to cantilever walls, obtained from

$$
\begin{aligned}
\omega_{v} & =0.9+\mathrm{n} / 10 \text { when } \mathrm{n} \leqq 6 \quad \text { (13a) } \\
\text { or } \quad \omega_{\mathrm{v}} & =1.3+\mathrm{n} / 30 \leqq 1.8 \text { when } \mathrm{n}>6
\end{aligned}
$$

where $\mathrm{n}$ is the number of storeys above the base.

The approach developed for the shear design of walls in hybrid structures is an extension of the two stage methodology used for cantilever walls 1,9 .

In the first stage, the design shear force is increased from the initial (Step 1) value to that corresponding with the development of a plastic hinge at flexural overstrength at the base of the wall. This is achieved with the introduction of the flexural overstrength factor, $\phi, w$ obtained in step 15. In the next stage, allowance is made for the amplification of the base shear force during the inelastic dynamic response of the structure. While a plastic hinge develops at the base of a wall, due to the contribution of higher modes of vibration, the centroid of inertia forces over the height of the building may be in a significantly lower position than that predicted by the conventional analysis for lateral loads ${ }^{9}$. The larger the number of storeys, the more important is the participation of higher modes. The dynamic shear magnification for cantilever walls, $\omega_{\mathrm{Y}}$, given in Eq. (13), makes allowance for this phenomenon ${ }^{9}$. The values so obtained agree with those recommended in NZS 3101 .

It has also been found, that for a given earthquake record, the dynamically induced base shear forces in walls of hybrid structures increased with an increased participation of such walls in the resistance of the total base shear for the entire structure. Wall participation is quantified by the "shear ratio". $\psi$, obtained in step 16. The effect of the "shear ratio" upon the magnification the maximum wall shear force is estimated by Eq. (12). It is seen that when $\psi=1, \omega_{\mathrm{V}}^{*}=\omega_{\mathrm{v}}$.
Design criteria for shear strength ${ }^{1}$ will often be found to be critical. At the base the thickness of walls may need to be increased on account of Eq. (11), and because of the maximum shear stress limitations of NZS 3101. Typically when using Grade 380 vertical wall reinforcement in a 12 storey hybrid structure, where the walls have been assigned $60 \%$ of the total base shear resistance, it will be found that with $\phi_{0, \mathrm{w}} \simeq 1.6, \omega_{\mathrm{V}}=1.7, \psi=0.6$ and $\omega_{\mathrm{V}}^{*}=1.42$ the ideal shear strength will need to be $\mathrm{V}_{\text {wall }}=2.27 \mathrm{~V}_{\text {code. }}$. In comparison, the ideal shear strength of a wall, proportioned with strength rather than capacity design procedures, would be $\mathrm{V}_{\text {wall }}=\mathrm{V}_{\text {code }} / 0.85=$ $1.18 \mathrm{~V}_{\mathrm{code}}$. Thus Eq. (II) implies very large apparent reserve strength in shear. Analyses in cases studiedll consistently predicted, however, shear forces which are often 30\% larger than those required by Eqn. (11). Of all the aspects of this proposed design strategy, the estimation of wall shear forces was found to be the least satisfactory. Some relevant issues are discussed subsequently in section 4.4 .

Step 18 - In each storey of each wall, provide shear resistance not less than that given by the shear design envelope of Fig. 10.

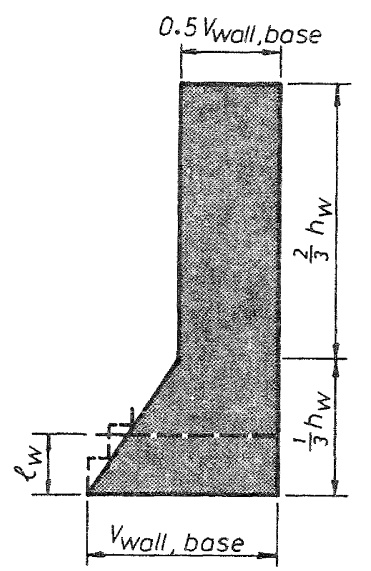

Fig. 10 Envelope for Design Shear Forces for Walls of Hybrid Structures

As Fig. 2 (c) shows, shear demands predicted by analyses for static load may be quite small in the upper half of walls. As can be expected, during the response of the building to vigorous seismic excitations, much larger shear forces may be generated at these upper levels. A linear scaling up of the shear force diagram drawn for static load, in accordance with $\mathrm{Eq}$. (11), would give an erronous prediction of shear demands in the upper storeys. Therefore from case studies the shear design envelope shown in Fig. 10 was developed. It is seen that the envelope gives the required shear strength in terms of the base shear for the wall, which was obtained in step 17.

Figure 11 presents some results of the relevant study 11 of a 12 storey building. It is seen that the shear design envelope is satisfactory when structures with relatively slender walls, with $\psi \leq 0.57$, were subjected 

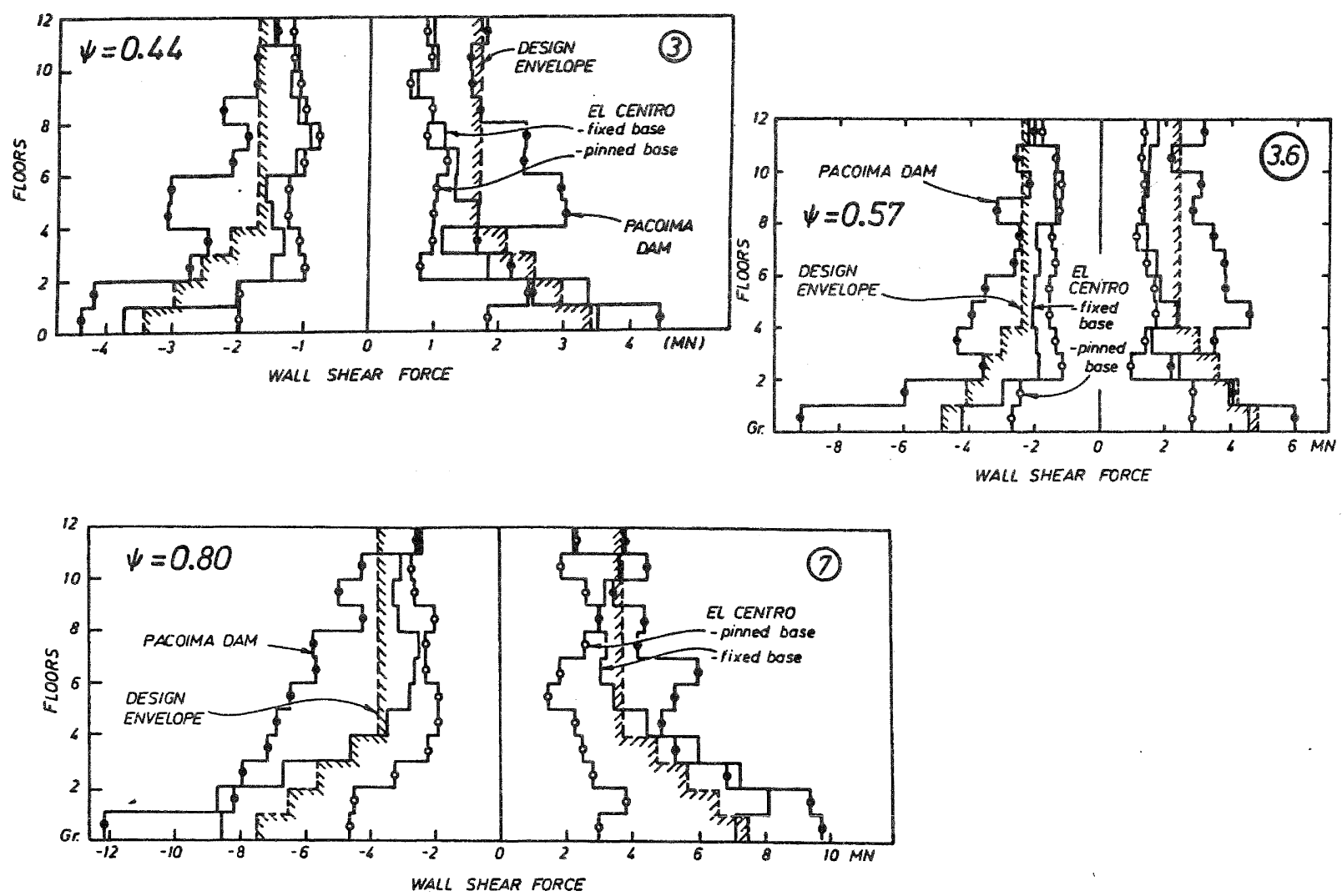

Fig. 11 Predicted Shear Demands for Different Walls in a 12 storey Hybrid Structure.

to the E1 centro excitation. The shear response of the structure with $7 \mathrm{~m}$ walls is less satisfactory in the lower storeys. As may be expected, the predicted demand for shear in pin based walls* is less, particularly as the length of the walls, $\ell_{W}$, increases. Shear loads predicted for the Pacoima event were found to consistently exceed the suggested design values.

With the aid of the shear design envelope, the required amount of horizontal (shear) wall reinforcement at any level may be readily found. In this, attention must be paid to the different approaches used ${ }^{l}$ to estimate the contribution of the concrete to shear strength, $v_{C}$, in the potential plastic hinge and the elastic regions of a wall. In the potential plastic hinge region, extending $l_{w}$ above the base, as shown in Fig. 10 , the major part of the design shear, $V_{\text {wall }}$, will need to be assigned to shear reinforcement. In the upper (elastic) parts of the wall, however, the concrete may be relied on ${ }^{1}$ to contribute significantly to shear resistance, allowing considerable reduction in the demand for shear reinforcement.

Step 19 - In the end regions of each wall, over the assumed length of the potential plastic hinge, provide adequate trans-

*Note that the shear ratio, $\psi$, given by Eq. (10), is not applicable to pin based walls. verse reinforcement to supply the required confinement to parts of the flexural compression zone and to prevent premature buckling of vertical bars.

These detailing requirements for ductility are the same 1 as those recommended for cantilever and coupled structural walls. Recent experimental studies ${ }^{11}$ indicated, however, that current code requirements, relevant to the region of confinement within wall sections, should be amended. For this reason, although presented elsewherelo, the suggested improvement in the procedure is restated here.

The proposed approach to the confinement of wall sections rests on the precept that concrete should be laterally confined wherewherever compression strains, corresponding with the expected curvature ductility demand on the relevant section, exceed 0.004 . The strain profile shown shaded in Fig. 12

indicates the ultimate curvature, $\phi_{\mathrm{u}}$, which might be necessary to enable the estimated displacement ductility, $\mu \Delta$, for a particular hybrid structure to be sustained, when the concrete strain in the extreme compression fibre theoretically reaches the magnitude of 0.004 . This strain profile is associated with a neutral axis depth, $c_{C}$. An estimate for this critical neutral axis depth, $c_{C}$, may be made ${ }^{1}$ with

$$
c_{c}=0.10 \phi_{0}^{*} \mathrm{~s} l_{w}
$$




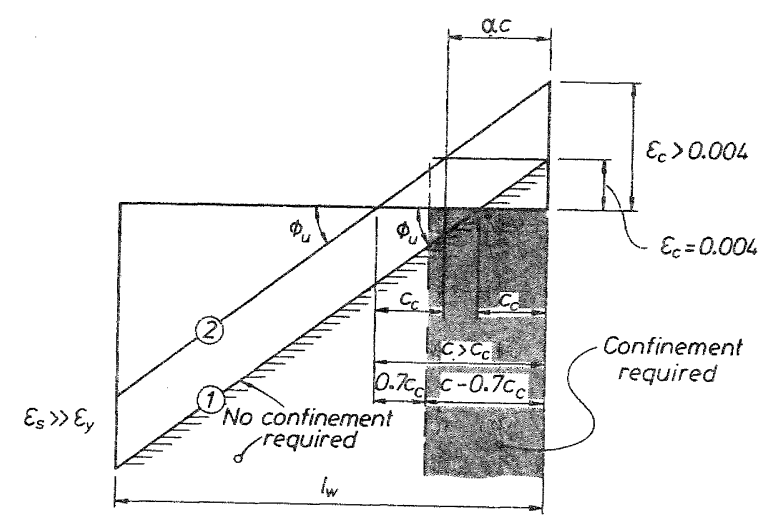

Fig. 12 Strain Profiles for wall Sections.

where $\ell_{\mathrm{w}}=$ length of wall,

$S=$ structural type factor ${ }^{2}$, and

$\phi_{0}^{*}=$ global overstrength factor, which is the ratio of the total resistance of the hybrid structure to overturning moment, including the contributions of axial forces in columns and walls and those of plastic hinges at the base of all columns and walls, evaluated at levels of flexural overstrength, to the corresponding overturning moment due to code specified lateral static loading: When the total strength provided by yielding regions of the structure matches very closely that required by the lateral code loading, the value of $\phi_{0}^{*}$ will not be less than 1.4 .

To achieve in a wall the same ultimate curvature when the computed neutral axis depth, c, is larger than the critical value, $\mathrm{c}_{\mathrm{C}}$, as Fig. 12 shows, the length of wall section subjected to compression strains larger than 0.004 , becomes ac. It is this length over which the compressed concrete needs to be confined. From the geometry shown in Fig. 12, $\alpha=1-c_{c} / c$.

Because it has been found in test, 10,11 that, after reversed cyclic loading, observed neutral axis depths tend to be larger than those predicted by conventional section analyses, it is suggested that the length of confinement, $\alpha c$, be derived from

$$
\alpha=1-0.7 \mathrm{c}_{\mathrm{C}} / \mathrm{C} \geqq 0.5
$$

whenever $\mathrm{C}_{\mathrm{C}} / \mathrm{c}<1$. When $\mathrm{c}$ is only a little larger than $c_{c}$, a very small and impractical value of $\alpha$ would be obtained. In line with current requirements ${ }^{1}$, it is suggested that in such cases at least one half of the theoretical compression zone be confined.

The tests quoted ${ }^{10}$ also indicated that the amount of confining reinforcement specified in the codel is likely to be adequate.

\section{ISSUES REQUIRING FURTHER STUDY}

The proposed capacity design procedure and the accompanying discussion of the behaviour of hybrid structures, presented in the previous section, are by necessity restricted to simple and regular structurai systems. The variety of ways in which walls and frames may be combined may present problems to which a satisfactory solution will require, as in many other structures, the application of engineering judgement. This may necessitate some rational adjustments in the outlined 19 step procedure. In the following, a few situations are mentioned where such judgement in the application of the proposed design methodology will be necessary. Some directions for promising approaches are also suggested.

\section{1 Gross Irregularities in the Lateral Load Resisting System.}

It is generally recognised that the larger the departure from symmetry and regularity in the arrangement of lateral load resisting substructures within a building, the less confidence should the designer have in predicting likely seismic response.

Examples of irregularity are when wall dimensions change drastically over the height of the building or when walls terminate at different heights, and when setbacks occur. Symmetrical positioning of walls in plan may lead to gross eccentricities of applied lateral load with respect to centres of rigidity.

\subsection{Torsional Effects}

Codes make simple and rational provisions for torsional effects. The severity of torsion is commonly quantified by the distance between the centre of rigidity (or stiffness) of the lateral load resisting structural system and the centre of mass. In reasonably regular and symmetrical buildings this distance (horizontal eccentricityl, does not significantly change from storey to storey. Errors due to inevitable variations of eccentricity over building height are thought to be compensated for by code specified amplifications of the computed (static) eccentricities. The corresponding assignment of additional lateral load to resisting elements, particularly those situated at greater distances from the centre of rigidity (centre of horizontal twist), are intended to compensate for torsional effects. Because minimum and maximum eccentricities, at least with respect to the two principal directions of earthquake attack, need to be considered, the structural system, as designed, will possess increased translational rather than torsional resistance.

It was emphasised that the contributions of walls to lateral load resistance in hybrid structures usually change dramatically over the height of the building. An example was shown in Fig. 2(c). For this reason the position of the centre of rigidity may also change significantly from floor to floor.

For the purpose of illustrating the variation of eccentricity with height, consider the example structure shown in Fig. 2(a), but slightly modified. Because of symmetry, torsion due to variation in the position of the centre of rigidity, does not arise. Assume, however, that instead of the two symmetrically positioned walls shown in Fig. 2(a), two $6 \mathrm{~m}$ long walls are placed side by side at $9.2 \mathrm{~m}$ from the left hand end 


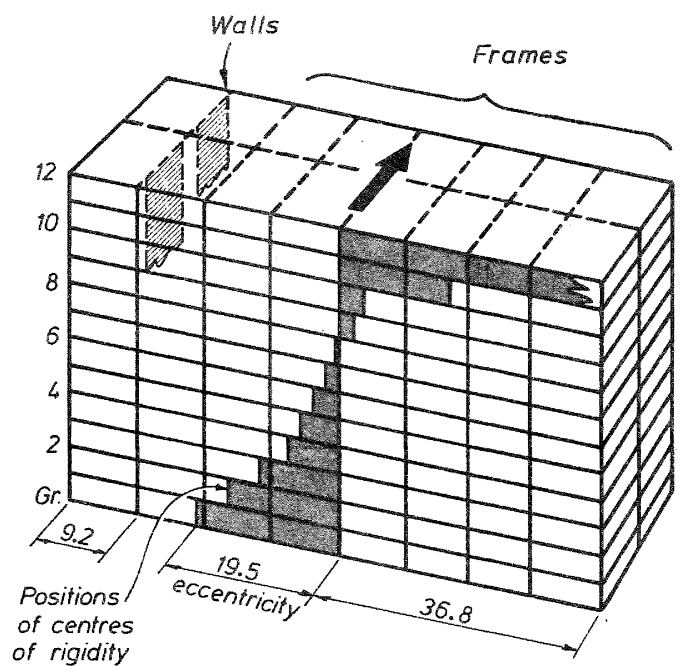

Fig. 13 The Variation of Computed Torsional Eccentricities in an Unsymmetrical 12 Storey Hybrid Structure.

of the building, as shown in Fig. 13, and that the right hand wall is replaced by a standard frame. Because the two walls, when displaced laterally by the same amount as the frames, would in this example structure resist $74 \%$ of the total shear in the first storey, the centre of rigidity would be $19.5 \mathrm{~m}$ from the centre of the (mass) building. In the 8th storey the two walls become rather ineffective, as they resist only about $12 \%$ of the storey shear i.e. approximately as much as one frame. At this level the eccentricity becomes negligible. As Fig. 13 shows, the computed static eccentricities would vary considerably in this example building between limits at the bottom and top storey. Note also the different senses. Torsional effects on individual columns and walls will depend on the total torsional resistance of the system, including the periphery frames along the long sides of the building.

\subsection{Diaphragm Flexibility.}

For most buildings, floor deformations associated with diaphragm actions are negligible. However, when structural walls resist a major fraction of the seismicaliy induced inertia forces in long and narrow buildings, the effects of inplane floor deformations upon the distribution of resistance to frames and walls may need to be examined.

(a)

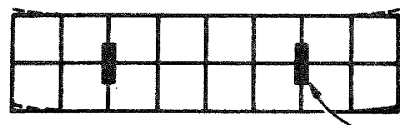

(b)

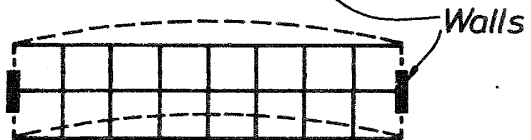

(c)

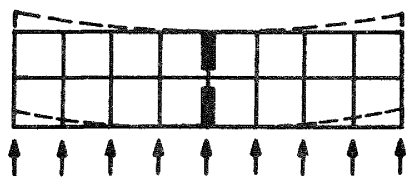

Figure 14 shows plans of a building with three different positions of identical walls. The building is similar to that shown in Fig. 2(a). The contribution of the two walls to total lateral load resistance is assumed to be the same in each of these three cases. Diaphragm deformations associated with each case are shown approximately to scale by the dashed lines. Diaphragm deformations in the case of Fig. 14(a) would be negligibly small in comparison with those of the other two cases. In deciding whether such deformations are significant, the following aspects might be considered:

(a) If elastic response is considered, the assignment of lateral load to some frames (Figs. 14 (b) and (c)) would be clearly urderestimated if diaphragms were to be assumed to be infinitely rigid. Inplane deformations of floors, even when derived with crude approximations, should be compared with interstorey drifts predicted by standard elastic analyses. Such a comparison will then indicate the relative importance of diaphragm flexibility.

(b) In ductile structures, significant inelastic storey drifts are to be expected. The larger the inelastic deformations the less important are differential elastic displacements between frames which would result from diaphragm deformations.

(c) As Fig. 2(c) illustrated, the contribution of walls to lateral load resistance in hybrid structures diminishes with the distance measured from the base. Therefore at upper floors, lateral load will be more evenly distributed among identical frames. This will greatly reduce diaphragm inplane shear and flexural actions. Hence diaphragn deformations at upper levels would diminish.

(d) Horizontal inertia forces are expected to increase with the distance from the base, while inplane bending and shear effects will diminish because of the decreasing participation of walls at upper floors. Hence it may be concluded that diaphragm flexibility is of lesser importance in hybrid structures of the type shown in Fig. 14, than in buildings where lateral load resistance is provided entirely by cantilever walls i.e. without the participation of any frames.

\subsection{Prediction of Shear Demand in Walls.}

A number of case studies for structures of the type shown in Fig. 2, typically with
$3.0,3.6$ and 7.0 long walls, have indicated that the capacity design procedure set out in section 3, led to structures in which:

(a) Inelastic deformations during the EI Centro event remained within limits currently envisaged in New Zealand. Typically storey drifts did not exceed 18 of storey heights.

Plastic hinges in the columns of upper storeys were not predicted.

Derived column design shear forces proscribed shear failure without the use of excessive shear reinforcement.

Fig. 14 Diaphragm Flexibility. 
(d) Rotational ductility demands at the base of both columns and walls. remained well within the limits readily attained in appropriately detailed laboratory specimensio.

(e)

Predicted shear demands in the upper storeys of walls were satisfactorily catered for by the envelope shown in Fig. 10 . However, maximum dynamic shear forces at the bases exceeded the design shear level (Fig. 11).

This latter feature was initially viewed with concern. Therefore a further study of the phenomenon, discussed previously with the description of design steps 17 and 18 , was undertaken. Some of the findings of this study are summarised in the following.

Firstly the incidence of the largest wall base shear forces and moments, analytically predicted for the El Centro event, was studied. This was achieved by recording the status of a wall base every $1 / 10$ seconds

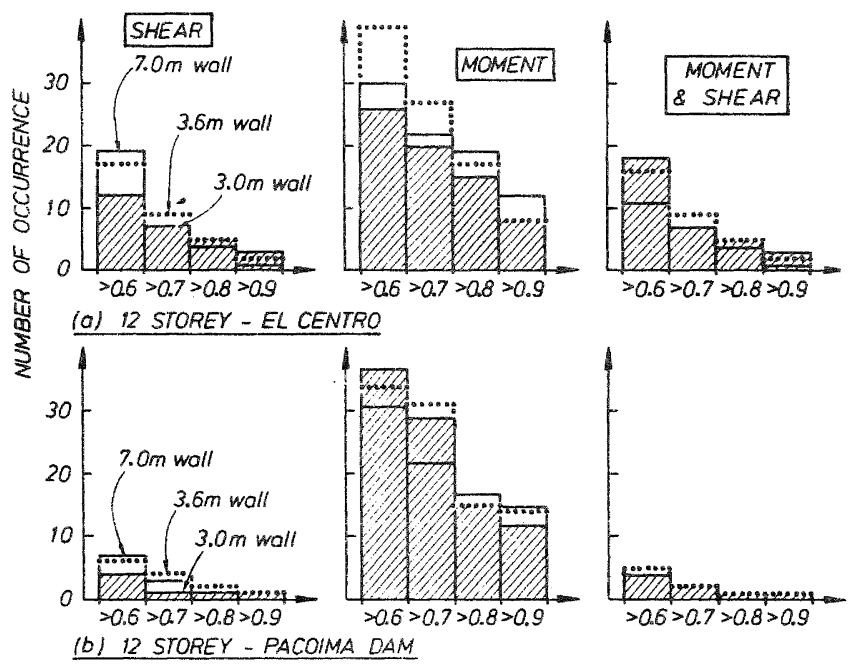

Fig. 15 Occurrence of High Shear Forces and Moments During the $\mathrm{El}$ Centro Event at the Base of the Walls of a 12 Storey Hybrid Structure.

during the first 10 seconds excitation. Figure 15 (a) shows for the El Centro event the frequency of occurrence during these first 10 seconds of the record of ranges of normalized high shear or moment intensities, as well as the concurrent occurrence of both. Intensities of shear or moment were expressed in terms of absolute maxima encountered during the record and shown in Fig. 11. It is seen for example that when $7 \mathrm{~m}$ walls were used, the base shear in excess of $60 \%$ of the absolute maximum was encountered 19 times. Similarly shear load on the $3 \mathrm{~m}$ wall larger than $90 \%$ of the maximum, was encountered 3 times. In the $3.6 \mathrm{~m}$ long walls, base moments in excess of $90 \%$ of the maximum, were encountered 8 times during the 10 seconds of El Centro record.

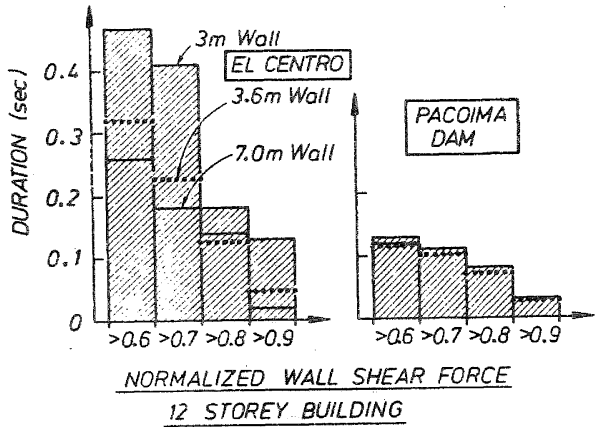

Fig. 16 Duration of Large Wall Shear Forces and Base Moments in walls of a 12 Storey Hybrid Structure

As expected, such frequency distributions are strongly dependent on the characteristics of the earthquake record. As Fig. 15(b) shows, the pattern is different for the extremely severe Pacoima Dam record. While moment demands during the two different seismic events were comparable, the frequency of large shear forces and large. concurrent shear and moment demands were significantly less during the pacoima event. For reasons of computational economy, sampling was at $1 / 10$ seconds intervals, even though the time step used in the analyses was $1 / 100$ seconds. A sampling at 1000 instants would have yielded an increase in the number of occurrences of shear levels of concern.

Figure 16 provides additional useful information. Here the total time during which a certain intensity of shear, in terms of the maximum, was exceeded during the 10 seconds of two different earthquake records is presented. This gives a more reassuring picture. When compared with Fig. 15(a), it is seen for example that during the $E I$ Centro event, the total time during which the predicted shear in the $3 \mathrm{~m}$ walls exceeded $90 \%$ of the maximum, (on three occasions) was only 0.12 seconds. Similarly the predicted duration of the 19 occurrences of shear in the $7 \mathrm{~m}$ walls, larger than $60 \%$ of maximum, was only 0.26 seconds. The computed duration of shears larger than $90 \%$ of the maximum, never exceeded 0.05 seconds during the El Centro event.

Although it is stressed that the prohibition of shear failure is of paramount importance in seismic design, it was concluded at the end of this study that the concern stemming from the less than satisfactory correlation between recommended design shear force levels for walls with maxima obtained from analytical predictions, could be dismissed because:

(a) Predicted peak shear forces were of very short durations. While there was no experimental evidence to prove it, it was felt that shear failures during real earthquakes could not occur within a few hundredths of a second. 
(b)

The probable shear strength of a wall. which could be utilized during such an extreme event, is in excess of the ideal strength (Eqn. (11)) used in design.

(c) Some inelastic shear deformation during the very few events of peak shear should be acceptable.

(d) Wa11s and columns were found not to be subjected simultaneously to peak shear demands. Therefore the danger of shear failure at the base, for the building as a whole, should not arise.

(e) The simultaneous occurrence during an earthquake record of predicted peak shear and peak flexural demands was found to be about the same as the occurrence of peak shear demands. This means that when maximum shear demand occurred, it did generally coincide with maximum flexural demands. Present code provisions ${ }^{l}$ were based on this precept. While the relevant code provisions do not affect the amount of shear reinforcement to be used, they ensure that wall thickness is large enough to keep shear stresses during such events at moderate levels.

\subsection{Variations in the Contribution of}

The study of the seismic response of hybrid structures has shown, as was to be expected, that the presence of walls significantly reduced the dynamic moment demands on columns. This is because the mode shapes of relatively stiff walls, do not permit extreme deformation patterns in the inherently more flexible columns. Therefore moment increases in columns above or below beams, due to higher mode effects, as shown in Fig. 7, are much smaller. This was recognised by the introduction of a smaller dynamic moment magnification factor, $\omega=1.2$, at intermediate floors, as discussed in design step 11 and shown in Fig. 6. The applicability of appropriate values for $w$ was supported. with a number of case studies., Il, in which walls made a significant contribution to the resistance of design base shear.

The contribution of all walls to lateral load resistance was expressed by the wall shear ratio, $\psi$, introduced in design step 16. The minimum value used in the example structure with two $3 \mathrm{~m}$ walls was 0.44

The question arises as to the minimum value of the wall shear ratio, $\psi$, relevant to a hybrid structure, for the design of which the proposed procedure in section 3 is still applicable. As the value of $\psi$ diminishes, indicating that lateral load resistance must be assigned primarily to frames, parameters of the design procedure must approach values applicable to framed buildingsl. At a sufficiently low value of this ratio, say $\psi<0.1$, a designer may decide to ignore the contribution of walls. Walls could then be treated as secondary elements which would need to follow, without distress, displacements dictated by the behaviour of ductile frames.

The minimum value of $\psi$ for which the procedure in section 3 is applicable has not been established. It is felt that $\psi=0.33$ might be an appropriate limit. For hybrid structures for which $0.1<\psi<0.33$, a linear interpolation of the relevant parameters, applicable to ductile frames and ductile hybrid structures, seems appropriate. These parameters are $\omega^{\prime} \omega_{\mathrm{C}} \omega_{\mathrm{v}}^{*}$ and $R_{\mathrm{m}}$

\section{SUMMARY}

(1) The methodology emboaied in current capacity design procedures used in New Zealand, relevant to both ductile framed buildings and those in which seismic resistance is provided entirely by structural walls, has been extended to encompass hybrid structures. Appropriate values were suggested for governing design parameters.

Regular 6 and 12 storey buildings with varying wall contents were designed using this approach, and subsequently subjected in analytical studies to the El Centro and Pacoima Dam accelerograms. The generally good performance of these buildings during the El Centro excitation suggested that prototype structures should exhibit good seismic performance.

(3) As intended, energy dissipation was found to occur primarily in beam and wall base plastic hinge zones.

Columns were found to enjoy protection against flexural yielding except at the base and top floor levels, where hinge formation was expected. A dynamic magnification factor for column moments of $\omega=1.2$ proved satisfactory

Column design shear forces were adequately predicted by the design procedure and generally found to be noncritical.

The provisions of the linear design wall moment envelopes restricted significant inelastic wall deformations, even during the extreme Pacoima Dam event, to the base.

(7) Peak wall base shear forces encountered during analyses were somewhat underestimated by the proposed design procedure. In the context of uncertainties in the analysis: available reserve shear strength, and in particular the predicted very short duration of these shear forces it was felt that this analytically predicted phenomenon should not be viewed with concern.

The proposed envelopes for design wall shear forces adequately estimated upper level shear demands.

(9) It is believed that the methodology proposed is logical and straight-

forward. It should provide buildings so designed, and carefully detailed, with excellent seismic performance capability.

Using engineering judgement, the approach is capable of being extended to other structural configurations not covered in this paper, but only by consistent application of capacity design principles. 
(11) The excellent seismic behaviour of well balanced interacting ductile frame-wall structures, particularly in terms of drift control and dispersal of energy dissipating mechanisms throughout the structural system, should encourage their extensive use in reinforced concrete buildings.

\section{ACKNOWLEDGEMENTS}

This study, being part of a project which involved also considerable experimental work, would not have been possible without generous grants from the New zealand Ministry of Works and Development and the University Grants Committee. Thanks are due to Mrs. V. Grey for preparation of illustrations, Mr. L. Gardner for photographic work and Mrs. J.Y. Johns for typing the text. The authors wish to acknowledge specially the invaluable assistance and advice received from $D r$. A.J. Carx with respect to computational work.

\section{REFERENCES}

1. NZS 3101:1982, Parts 1 and 2, "Code of Practice for the Design of Concrete Structures", Standards Association of New Zealand, Wellington, $283 \mathrm{pp}$.

2. Paulay, T. and Williams, R.L., "The Analysis and Design of and the Evaluation of Design Actions for Reinforced Concrete Ductile Shear Walls", Bulletin of the New Zealand National Society for Earthquake Engineering, Vol. 13, No. 2, June 1980, pp.108-143.

3. Goodsir, W.J., Paulay, T, and Carr, A.J., "A Study of the Inelastic Seismic Response of Reinforced Concrete Coupled Frame - Shear wall Structures", Bulletin of the New Zealand National Society for Earthquake Engineering, Vol. 16, No. 3, sept. 1983, pp.185-200.

4. Goodsir, W.J., "The Response of Coupled Shear Walls and Frames", Research Report No. 82-10, Department of Civil Engineering, University of Cantexbury, Christchurch, New Zealand, $1982,155 \mathrm{pp}$.

5. NZS 4203:1984, "Code of Practice for General Structural Design and Design Loadings for Buildings", Standards Association of New Zealand, Wellington, $80 \mathrm{pp}$.

6. Khan, F.R. and Sbarounis, J.A., "Interaction of Shear Walls with Frames in Concrete Structures under Lateral Loads" Journal of the Structural Division, ASCE, Vol. 90, No. ST3, June 1964, pp.285-335.

7. Rosman, R., "Laterally Loaded Systems Consisting of Walls and Frames", Tall Buildings, University of Southhámpton, 1966, pp. 273-289.

8. Paulay, T., "Moment Redistribution in Continuous Beams of Earthquake Resistant Multistorey Reinforced Concrete
Frames", Bulletin of the New Zealand National Society for Earthquake Engineering, Vol. 9, Nol. 4, Dec. 1976, pp. $205-212$.

9. Blakeley, R.W.G., Cooney, R.C. and Megget, L.M., "Seismic Shear Loading at Flexural Capacity in Cantilever Walls", Bulletin of the New Zealand National Society for Earthquake Engineering, Vol. 8, No. 4, Dec. 1975, pp.278-290.

10. Paulay, T. and Goodsir, W.J., "The Ductility of Structural walls", Bulletin of the New Zealand National Society for Earthquake Engineering, Vol. 18, No. 3, Sept. 1985, pp.250269.

11. Goodsir, W.J., "The Design on Coupled Frame-Wall Structures for Seismic Actions", Research Report No. 85-8, Department of Civil Engineering, University of Canterbury, Christchurch, New Zealand, 1985, 383pp.

\section{LIST OF SYMBOLS}

A $\quad=$ gross concrete area of section

c $=$ theoretical neutral axis depth

$\mathrm{C}_{\mathrm{C}} \quad=$ critical neutral axis depth

$\mathrm{D}=$ dead load

$\mathrm{E} \quad=$ earthquake load

$f_{C}^{\prime} \quad=$ specified compression strength of concrete (MPa)

$h_{b} \quad=$ depth of beam

$I_{a}, I_{b}=$ second moment of area of beam sections

$I_{C} \quad=$ second moment of area of a column section

$I_{w}=$ second moment of area of a wall section

l $=$ span lengths

$\ell_{n} \quad=$ clear height of column

$l_{W} \quad=$ length of wall, overall depth of wall section

$\mathrm{L}_{\mathrm{R}} \quad=$ reduced live load

MDeam = flexural overstrength of beam measured at column centre line

$\mathrm{M}_{\text {code }}=$ moment due to code specified lateral load

$M_{\text {code, top }}=$ column moment at the top of a column derived from lateral code loading

$\mathrm{M}_{\mathrm{COl}}=$ design moment for a column at ideal strength

$\mathrm{M}_{\mathrm{Col}}^{\mathrm{O}}=$ flexural overstrength at a column section

MO = moment developed at flexural overstrength

$\mathrm{M}_{\mathrm{u}} \quad=$ moment due to factored loads

$\mathrm{n} \quad=$ number of storeys above a given level

$\mathrm{P}_{\mathrm{D}} \quad=$ axial load on column due to dead load $\mathrm{P}_{\mathrm{e}, \max }, \mathrm{P}_{\mathrm{e}_{\text {including }} \text { min earthquake effects }}=$ design axial load on column

$P_{e q} \quad=$ earthquake induced axial load in column at the development of beam overstrengths

$\mathrm{P}_{\mathrm{LR}}=$ axial load on column due to reduced live load

$\mathrm{P}_{\mathrm{u}} \quad=$ axial load due to factored loads

$\mathrm{R}_{\mathrm{m}}=$ column design moment reduction factor 


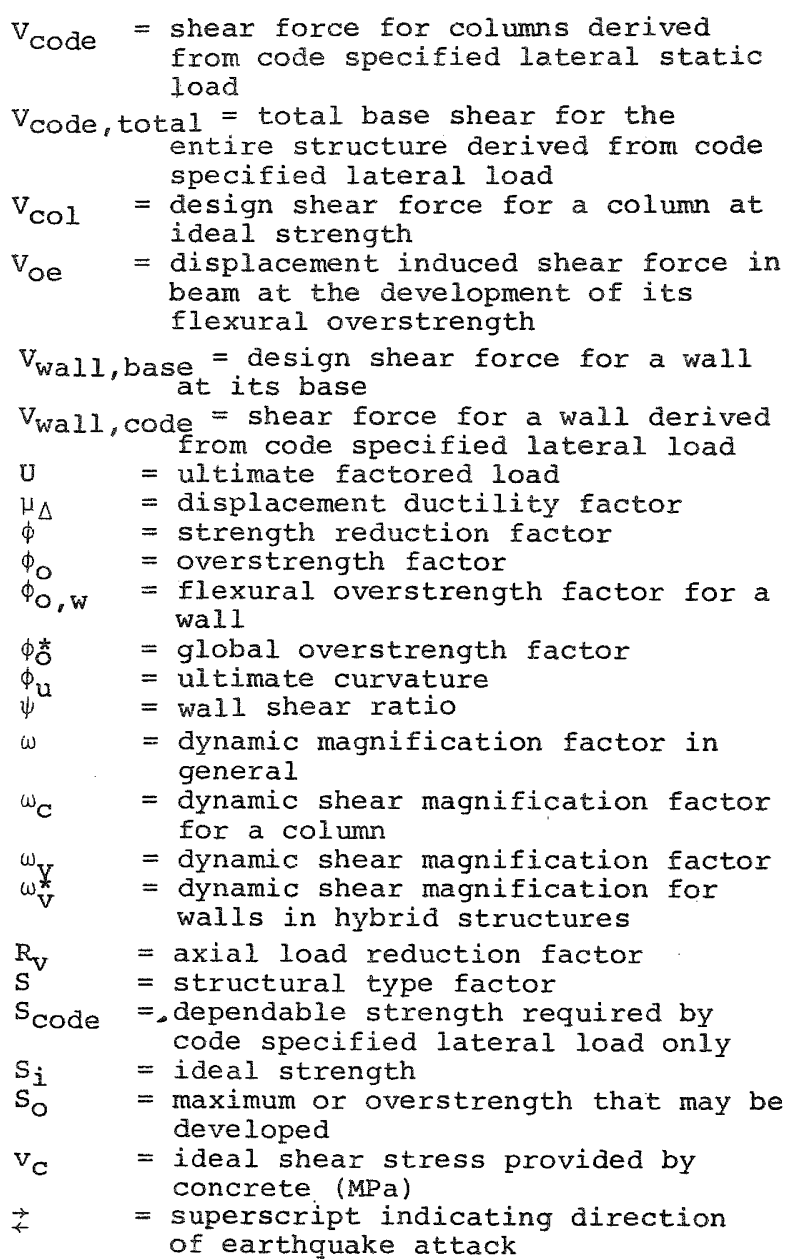

